\title{
LA IMPLEMENTACIÓN DE LOS CRÍMENES DE COMPETENCIA DE LA CORTE PENAL INTERNACIONAL EN LA LEY N ${ }^{\circ} 20.357^{*}$
}

\author{
Claudia Cárdenas Aravena**
}

RESUMEN

\begin{abstract}
El texto se dedica a la Ley $N^{\circ} 20.357$, que tipifica los crimenes de lesa humanidad y genocidio y crímenes y delitos de guerra en la ley chilena. Revisa sus disposiciones, tanto las de la parte especial como las de la parte general, a fin de dilucidar si es que la ley cumple con el fin declarado al legislar, que es el de garantizar que los tribunales chilenos, en aplicación de legislación nacional, puedan ejercer su competencia para los crimenes contra el derecho internacional de competencia de la Corte Penal Internacional. Se concluye que si bien la implementación es un avance muy relevante en la materia, el objetivo declarado no se cumple a cabalidad, puesto que en algunos aspectos el legislador chileno decide innovar, haciendo que el ámbito de aplicación de esta ley sea, en más de una ocasión, más estrecho que la competencia de la Corte Penal Internacional, sin que en la historia de la ley se encuentren justificaciones para este proceder.
\end{abstract}

\section{CRÍMENES CONTRA EL DERECHO INTERNACIONAL - CORTE PENAL INTERNACIONAL - LEY 20.357}

\section{The regulation of the crimes under the jurisdiction of the International Criminal Court in Act $N^{0} 20.357$}

\begin{abstract}
The text is focused on Act $N^{\circ} 20.357$, which regulates crimes against bumanity and genocide, and war crimes in Chilean legal system. It looks through its regulations, both of the general as well as the special part, with the objective of clarifying if the statute is coherent with its declared purpose, which is to guarantee that Chilean courts, in the application of national legislation, are able to exercise their jurisdiction over the same crimes against international law that are assigned to the jurisdiction of the International Criminal Court. It is concluded that albeit its implementation is a very relevant step forward in this field, the declared objective is not upheld in its entirety, due to the fact that in certain aspects the Chilean Act tend to innovate, making the scope of its application more limited than the jurisdiction of the International Penal Court, even though there is no justification for this restrictions in the Act's bistory.
\end{abstract}

\section{CRIMES AGAINST INTERNATIONAL LAW - INTERNATIONAL}

CRIMINAL COURT - ACT 20357

* Este trabajo cuenta con el patrocinio de FONDECYT (Proyecto $\mathrm{N}^{\circ}$ 1080060). El texto de este artículo está basado en una ponencia presentada en el Seminario "Chile y la Corte Penal Internacional", organizado por la Facultad de Derecho de la Universidad Diego Portales el 1 de diciembre de 2009.

** Abogada, Magíster y Doctora en Derecho, Profesora de Derecho en la Facultad de Derecho de la Universidad de Chile, Santiago de Chile, cardenascl@yahoo.de

Artículo recibido el 23 de febrero de 2010 y aceptado para su publicación por el Comité Editorial el 27 de octubre de 2010 . 


\section{INTRODUCCIÓN}

L a ratificación del Estatuto de la Corte Penal Internacional tuvo un larguísimo trámite en nuestro país ${ }^{1}$. Más de una década demoró, y tuvo como hitos, primero, la sentencia del Tribunal Constitucional que declaró que era necesaria una reforma constitucional previa a la ratificación ${ }^{2}$ y, luego, la condición de los partidos de la oposición de entonces de despachar, antes de la reforma constitucional que posibilitaría la ratificación del tratado, una ley que asegurara la competencia de los tribunales chilenos sobre los crímenes contra el derecho internacional de competencia de la Corte Penal Internacional, a fin de minimizar las opciones de que ella pudiera ejercer su jurisdicción complementaria sobre hechos ocurridos en el territorio nacional ${ }^{3}$. Fue así que se tramitó la que hoy rige como Ley $\mathrm{N}^{0} 20.357$, publicada en el Diario Oficial el 18 de julio de 2009, que tipifica los crímenes de lesa humanidad y genocidio y crímenes y delitos de guerra en la ley chilena.

El Estatuto de la Corte Penal Internacional no es fuente, para sus Estados Partes, de una obligación jurídica de implementar en su derecho interno a los crímenes contra el derecho internacional (conductas cuya punibilidad arranca directamente a partir del derecho internacional $)^{4}$. Dicho Estatuto sólo exige que los Estados Partes modifiquen su legislación en dos áreas: conforme a su artículo 88 deben implementar procedimientos para todas las formas de cooperación previstas en la parte 9 del Estatuto; y conforme a su artículo 70 párrafo 4 deben hacer extensiva su legislación contra la integridad de su propio procedimiento de investigación o enjuiciamiento a los delitos contra la administración de justicia ante la Corte que sean cometidos en su territorio o por uno de sus nacionales.

${ }^{1}$ En enero de 1999 se envió al Congreso Nacional el primer proyecto para aprobar el Estatuto, trámite previo a su ratificación por el Estado de Chile. Finalmente la aprobación del Estatuto de Roma de la Corte Penal Internacional por el Congreso Nacional consta en el Oficio del Senado No 558/SEC/09, de 25 de junio de 2009.

${ }^{2}$ Sentencia de 8 de abril de 2002, puede ser consultada en >http://www.tribunalconstitucional.cl/ index.php/sentencias/download/pdf/274< (visitado en febrero de 2010). La sentencia generó controversia en la época de su dictación, y fue objeto de comentarios, también por parte de académicos. Entre ellos destacan el de Nogueira Alcalá, H., "Consideraciones sobre el Fallo del Tribunal Constitucional Respecto del Tratado de Roma que Establece la Corte Penal Internacional” en Ius et Praxis, Universidad de Talca, 8(1): 2002, pp. 563-581; y Cazor Aliste, K. / Bordalí Salamanca, A., "La Corte Penal Internacional ante la Constitución de 1980 (comentarios al fallo del Tribunal Constitucional de fecha 8 de abril de 2002)", en Revista de Derecho, Universidad Austral de Chile, vol. XIII, diciembre 2002, pp. 255-263.

${ }^{3}$ Moción de los senadores Alberto Espina, José Antonio Gómez, Hernán Larraín, Pedro Muñoz, Mariano Ruiz-Esquide, de 11 de marzo de 2009. Puede ser consultada en >http://recursoslegales.bcn.cl/jspui-rl/ bitstream/10221.3/3840/2/HL20357.pdf< (visitado en febrero de 2010). La misma idea se reitera durante la tramitación, que puede ser consultada en la misma fuente. Sobre el principio de complementariedad, cfr. Cárdenas Aravena, C., "La Corte Penal Internacional y su relación con las jurisdicciones nacionales: El principio de complementariedad", en Revista de Magíster y Doctorado en Derecho, Universidad de Chile. $\mathrm{N}^{\mathrm{o}} 1 / 2007$, pp. 123-138.

${ }^{4}$ Cabe señalar, a efectos aclaratorios, que en el derecho internacional se utiliza la voz “crimen" para referirse a todas las conductas punibles, no teniendo por lo tanto el término la misma acepción que en el derecho interno chileno. 
Si bien puede argumentarse que la obligación de implementar los crímenes contra el derecho internacional existía para Chile con fuentes diversas del Estatuto de la Corte Penal Internacional ${ }^{5}$, de la Historia de la Ley ${ }^{6}$ resulta evidente que el detonante de esta legislación no fue principalmente el imperativo de cumplir con deberes jurídicos, sino la conveniencia jurídica de implementar, como precaución, buscando impedir que la Corte Penal Internacional pueda ejercer su competencia complementaria sobre hechos acaecidos en Chile.

Independientemente de que se salude la implementación de crímenes contra el derecho internacional en la ley chilena ${ }^{7}$, y siendo éste el primer cuerpo legal chileno dedicado íntegramente al derecho penal internacional ${ }^{8}$, resulta pertinente examinar hasta qué punto esta legislación cumple con los fines que motivaron su dictación. Para ello abordaremos a la ley desde la perspectiva del Derecho Penal Internacional, sin pretender analizar todas sus aristas, sino que los aspectos que sean necesarios para determinar hasta qué punto se cumplió con la intención declarada por los parlamentarios de gobierno y de oposición que presentaron conjuntamente la moción que se convirtiera luego en la ley en comento.

\section{DERECHO PENAL MATERIAL}

En este acápite se abordará la tipificación chilena de los crímenes de derecho internacional, pues en algunos casos existen diferencias no del todo menores entre lo que dispone el derecho internacional y el derecho interno respecto de las conductas punibles. Se contrastarán las descripciones de la ley chilena con las del Estatuto de la Corte Penal Internacional, sin discutir en todos los casos su equivalencia exacta con el Estado actual del Derecho Penal Internacional en su conjunto, pues son los casos bajo la competencia de la Corte Penal Internacional los que la ley chilena pretende abarcar.

\footnotetext{
${ }^{5}$ Cfr. Cárdenas Aravena, C. "Los Crímenes del Estatuto de la Corte Penal Internacional en el derecho chileno, necesidad de una implementación”, en Política Criminal, Centro de Estudios de Derecho Penal de la Universidad de Talca, $\mathrm{N}^{\circ}$ 2/2006, pp. 7 y ss.

${ }^{6}$ Puede ser consultada en >http://recursoslegales.bcn.cl/jspui-rl/bitstream/10221.3/3840/2/HL20357. $\mathrm{pdf}<$ (visitado en febrero de 2010).

${ }^{7}$ Respecto de la necesidad de implementar, cfr. Cárdenas Aravena, C., "Los Crímenes del Estatuto de la Corte Penal Internacional en el derecho chileno, necesidad de una implementación”, en Política Criminal, Centro de Estudios de Derecho Penal de la Universidad de Talca, No 2/2006, pp. 1-17.

${ }^{8}$ Con esto Chile se une a la tendencia mundial de implementar crímenes contra el derecho internacional en el derecho interno. Numerosas legislaciones nacionales de implementación pueden ser revisadas en >http://www.legal-tools.org/en/access-to-the-tools/national-implementing-legislation-database/ < (visitado en febrero de 2010). Hasta antes de la entrada en vigor de esta ley, sólo normas individuales en el Código de Justicia Militar tipificaban algunas conductas constitutivas de crímenes contra el derecho internacional.
} 


\section{I.1. Categorías de crímenes}

Conforme al artículo 5 del Estatuto de la Corte Penal Internacional, su competencia material del tribunal abarca al genocidio, los crímenes de lesa humanidad, los crímenes de guerra y el crimen de agresión. La ley chilena se refiere solamente a las tres primeras categorías. Esto, que a primera vista pudiera parecer una omisión sustancial, en la práctica carece de significación, puesto que la Corte no puede, a la fecha, ejercer su competencia sobre el crimen de agresión a falta de una descripción, en el Estatuto, de aquello en lo que la conducta punible ha de consistir?.

Revisaremos a continuación separadamente las particularidades de la ley chilena respecto de las tres categorías de crímenes restantes, en el orden en que las trata la ley chilena.

\section{I.2. Crimenes de lesa bumanidad ${ }^{10}$}

La ley chilena $\mathrm{N}^{\circ} 20.357$ le dedica sus primeros artículos, desde el 1 al 10 .

Conforme al Estatuto de la Corte Penal Internacional, para los efectos de su competencia se entiende que son constitutivos de crímenes de lesa humanidad cualquiera de los actos que señala en un listado (artículo 7 párrafo 1$)^{11}$ cuando se cometan como parte de un ataque generalizado o sistemático contra una población civil y con conocimiento de dicho ataque. Vale decir, en la estructura del crimen pueden reconocerse un así denominado

\footnotetext{
${ }^{9}$ Cfr., respecto del crimen de agresión, por todos y con más antecedentes, Werle, G., Tratado de derecho penal internacional, Tirant Lo Blanch, Valencia, 2005, pp. 585 y ss. Vid. asimismo Cassese, A., "On Some Problematical Aspects of the Crime of Aggression”, en Leiden Journal of International Law 20 (2007), pp. 841 y ss.; Ferencz, B., "The Crime of Aggression", en Kirk McDonald, G./Swaak-Goldman, O. (editoras), Substantive and Procedural Aspects of International Criminal Law, The Experience of International and National Courts, tomo 1, Kluwer Law International, La Haya, 2000, pp. 33 y ss.; Politi, M./Nesi, G. (editores), The International Criminal Court and the Crime of Aggression, Ashgate Publishing, Adlershot, 2004, pp. 97 y ss.

${ }^{10}$ Cfr., por todos y con más antecedentes, Werle, G., Tratado de derecho penal internacional, Tirant Lo Blanch, Valencia, 2005, pp. 345 y ss. Vid. asimismo Bassiouni, M., Crimes Against Humanity in International Criminal Law, $2^{a}$ edición, Kluwer Law International, La Haya, 1999; Cryer, R., Prosecuting International Crimes, Selectivity and the International Criminal Law Regime, Cambridge University Press, Cambridge, 2005, pp 247 y ss.; Esposito, A./Gentile, G./Trapasso, M., "I Crimini Contro l’Umanità”, en Lattanzi, G./Monetti, V. (editores), La Corte Penale Internazionale, Giuffrè, Milán, 2006, pp. 600 y ss.; Hebel, H./Robinson, D., "Crimes within the Jurisdiction of the Court", en Lee, R. (editor), The International Criminal Court, The Making of the Rome Statute, Kluwer Law International, La Haya, 1999, pp. 79 y ss., 90 y ss.; Meseke, S.: Der Tatbestand der Verbrechen gegen die Menschlichkeit nach dem Römischen Startus des Internationalen Strafgerichtshofs, Berliner Wissenschaftsverlag, Berlín 2004.

11 a) Asesinato; b) Exterminio; c) Esclavitud; d) Deportación o traslado forzoso de población; e) Encarcelación u otra privación grave de la libertad física en violación de normas fundamentales de derecho internacional; f) Tortura; g) Violación, esclavitud sexual, prostitución forzada, embarazo forzado, esterilización forzada o cualquier otra forma de violencia sexual de gravedad comparable; h) Persecución de un grupo o colectividad con identidad propia fundada en motivos políticos, raciales, nacionales, étnicos, culturales, religiosos, de género definido en el párrafo 3, u otros motivos universalmente reconocidos como inaceptables con arreglo al derecho internacional, en conexión con cualquier acto mencionado en el presente párrafo o con cualquier crimen de la competencia de la Corte; i) Desaparición forzada de personas; j) El crimen de apartheid; k) Otros actos inhumanos de carácter similar que causen intencionalmente grandes sufrimientos o atenten gravemente contra la integridad física o la salud mental o física.
} 
"hecho global" (ataque generalizado o sistemático contra una población civil), que debe ser conocido por el agente, y los "hechos particulares" que se señalan en el listado ${ }^{12}$.

\section{I.2.a) Hecho global}

El Estatuto de la Corte Penal Internacional señala lo que entiende por ataque contra una población civil (artículo 7 párrafo 2 letra a) ${ }^{13}$. Esta descripción comprende, como consecuencia de las negociaciones y para los efectos de la competencia de la Corte, lo que se ha dado en llamar el "elemento político"14, de acuerdo al cual el ataque debe guardar "conformidad con la política de un Estado o de una organización de cometer ese ataque" o debe realizarse "para promover esa política".

La ley chilena, adoptando también el elemento político (artículo $1 \mathrm{~N}^{\circ} 2$ ), exige que el ataque (generalizado o sistemático contra una población civil) corresponda a una política, bien sea del Estado o de sus agentes o de "grupos armados organizados que, bajo la dirección de un mando responsable, ejerzan sobre algún territorio un control tal que favorezca la impunidad de sus actos”. Esta última variante supone un requisito más estricto que el del Estatuto: no bastará con que la política emane de una organización cualquiera, sino que ha de emanar de grupos con ciertas características. Si la política emanara de otros grupos, la conducta de que se trate no sería punible como crimen de lesa humanidad conforme a la ley chilena, pero sí quedaría, como tal, bajo la competencia de la Corte Penal Internacional.

El tenor literal de la descripción de los grupos armados en la Ley N 20.357 está tomado en parte del segundo Protocolo Adicional a los Convenios de Ginebra del 12 de agosto de $1949^{15}$, que en cualquier caso se refiere al derecho internacional humanitario, cuyas violaciones graves constituyen crímenes de guerra, y no a los crímenes de lesa humanidad. Estos últimos, ya desde los procesos en las zonas de ocupación de lo que era Alemania después de la Segunda Guerra Mundial, se castigan con independencia de un conflicto armado ${ }^{16}$. Es más, incluso en la definición que la ley chilena hace de conflicto

${ }^{12}$ Cfr., por todos y con más antecedentes, Werle, G., Tratado de derecho penal internacional, Tirant Lo Blanch, Valencia, 2005, pp. 356 y ss.

13 " [U]na línea de conducta que implique la comisión múltiple de [hechos individuales] contra una población civil de conformidad con la política de un Estado o de una organización de cometer ese ataque o para promover esa política".

${ }^{14}$ Se lo incluyó aunque hasta la fecha esa característica no ha sido considerada como elemento del delito. Cfr. sobre el particular y con más antecedentes Werle, G., Tratado de derecho penal internacional, Tirant Lo Blanch, Valencia, 2005, pp. 364 y ss.; Clark, R., "Crimes Against Humanity and the Rome Statute of the International Criminal Court”, en Politi M./Nesi G. (editores), The Rome Statute of the International Criminal Court, A challenge to impunity, Ashgate Publishing, Adlershot, 2001, p. 91.

${ }^{15}$ Protocolo Adicional a los Convenios de Ginebra del 12 de agosto de 1949 relativo a la protección de las víctimas de los conflictos armados sin carácter internacional (Protocolo II, de 1977), artículo 1. Consultado en >http://www.cicr.org/web/spa/sitespa0.nsf/html/protocolo-II< (visitado en febrero de 2010).

${ }^{16}$ Conforme a la Ley $N^{\circ} 10$ sobre el Castigo de Personas que sean culpables de haber cometido Crímenes de Guerra, Crímenes contra la Paz o Crímenes contra la Humanidad de 20 de diciembre de 1945 (conocida como Ley No 10 del Consejo de Control Aliado). 
armado interno para los efectos de los crímenes de guerra no se rige por lo dispuesto en esta convención, sino por parámetros más contemporáneos, siguiendo al Estatuto de la Corte Penal Internacional.

La última parte de la norma chilena en comento, que no está tomada del Protocolo, resulta también curiosa, puesto que si es que se llega a juicio es que el control del grupo armado sobre el territorio no favoreció la impunidad de sus actos.

Por otra parte, conforme al Estatuto de la Corte Penal Internacional, que fija la competencia de ese tribunal, los hechos individuales punibles como crímenes de lesa humanidad deben corresponder a la política en cuestión, o tener como fin el promoverla. El último supuesto no está contemplado en la ley chilena, con lo que el ámbito de punibilidad queda nuevamente constreñido en el derecho nacional si se toma como parámetro de comparación la competencia de la Corte Penal Internacional.

Para finalizar con las particularidades de la ley chilena en cuanto al hecho global en los crímenes de lesa humanidad, su artículo 2 contiene definiciones de lo que entiende por un ataque generalizado y uno sistemático, señalando como elemento diferenciador que un ataque es sistemático si se extiende por un periodo prolongado de tiempo. Esto contradice el tenor literal de la expresión y el sentido que la jurisprudencia internacional le ha dado ${ }^{17}$. En efecto, es incontestado que la prolongación en el tiempo de un ataque será un indicio de que obedece a un sistema o plan, pero no se divisa la necesidad de reducir la sistematicidad a ese solo indicador, como lo ha hecho nuestro legislador.

\section{I.2.b) Hechos individuales}

En cuanto a los hechos individuales, la ley chilena divide las conductas conforme a las penas que tienen asignadas. Para los efectos de este examen seguiremos el orden de los hechos individuales en el Estatuto de la Corte Penal Internacional ${ }^{18}$.

El hecho individual de asesinato (homicidio) está implementado en el artículo 3 de la Ley $\mathrm{N}^{\circ} 20.357$, con penas inferiores en su máximo a las de este supuesto de genocidio $^{19}$. El exterminio y la esclavitud están tipificados, respectivamente, en artículo 7 $\mathrm{N}^{\circ} 2$ y en el artículo $5 \mathrm{~N}^{\circ} 6$ de la Ley $\mathrm{N}^{\circ} 20.357$.

17 Werle, G., Tratado de derecho penal internacional, Tirant Lo Blanch, Valencia, 2005, p. 363; Bantekas, I/Nash, S: Internacional Criminal Law, 3 ra edición, Routledge-Cavendish, Londres, 2007, p. 130 y ss.; Cryer, R./Friman, H./Robinson, D./Wilmshurst, E., An Introduction to International Criminal Law and Procedure, Cambridge University Press, Cambridge, 2007, p. 195; Tribunal Penal Internacional para la ex Yugoslavia, sentencia de 7 de mayo de 1997, Tadich, TC), parág. 648; Tribunal Penal Internacional para Ruanda, sentencia de 2 de septiembre de 1998, (Akayesu, TC), parág. 580; Tribunal Penal Internacional para la ex Yugoslavia, sentencia de 3 de marzo de 2000 (Blaskic, TC), parág. 203; Tribunal Penal Internacional para la ex Yugoslavia, sentencia de 26 de febrero de 2001 (Kordic y Cerez, TC), parág. 179; (Tribunal Penal Internacional para la ex Yugoslavia, sentencia de 12 de junio de 2002 (Kunarac et al., AC), parág. 94; Tribunal Penal Internacional para Ruanda, sentencia de 21 de febrero de 2003 (Ntakirutimana, TC), parág. 804. Las sentencias pueden ser consultadas en $>$ www.icty.org $<y>$ www.ictr.org $<$ (consultadas en febrero de 2010).

${ }^{18}$ Cfr. nota $\mathrm{N}^{\mathrm{o}} 12$.

19 Esto da luces acerca de la posición del legislador chileno en cuanto a si alguno de los crímenes contra el derecho internacional es intrínsecamente más grave que los demás. En el ámbito internacional, si 
La deportación o traslado forzoso de población están recogidos en el artículo 9 de la Ley No 20.357. El Estatuto de la Corte Penal Internacional señala como requisito que el desplazamiento debe ser de la zona en que la población esté legítimamente presente y debe realizarse sin motivos autorizados por el derecho internacional. Esto hace que el ámbito de punibilidad en la ley chilena, que no contempla este requisito, sea a primera vista más amplio que el de la conducta descrita en el Estatuto pero, en la práctica, si hubiera motivos autorizados por el derecho internacional para el desplazamiento, habría una causal de justificación que haría que la conducta no fuera punible, por lo que los efectos de la diferencia de texto podrían no ser visibles en la práctica.

La encarcelación u otra privación grave de la libertad física en violación de normas fundamentales de derecho internacional como hecho individual está recogido en artículo $5 \mathrm{~N}^{\circ} 7$ de la Ley $\mathrm{N}^{\circ} 20.357$, con el requisito de que la privación de libertad sea por más de cinco días. Se regula expresamente el concurso con normas sobre secuestro (se aplica pena más alta).

La tortura está tipificada en artículo $7 \mathrm{~N}^{0} 1$ de la ley chilena, en términos equivalentes al Estatuto de la Corte Penal Internacional. En el inciso 2 se prevén algunos supuestos en los que se agrava la pena.

En cuanto a las conductas de violencia sexual ${ }^{20}$, el embarazo forzado esta tipificado en el artículo 5 inciso $1 \mathrm{~N}^{\circ} 5$ de la Ley $\mathrm{N}^{\circ} 20.357$, el aborto forzado en el $\mathrm{N}^{\circ} 4$, la esterilización forzada en el $\mathrm{N}^{\circ} 3$, la violación y abuso sexual en el $\mathrm{N}^{\circ} 8$, la prostitución forzada en el $\mathrm{N}^{\circ}$ 9; abuso sexual o violación de menores en artículo $8 \mathrm{~N}^{\circ} 3$ de la Ley $\mathrm{N}^{\circ} 20.357$.

La persecución de un grupo o colectividad con identidad propia fundada en motivos universalmente reconocidos como inaceptables con arreglo al derecho internacional ${ }^{21}$, que para que sea punible como crimen de lesa humanidad conforma al derecho penal internacional debe realizarse en conexión con cualquier crimen contra el derecho internacional, no está implementado en el derecho chileno como delito específico, sino como agravante en el artículo 39 de la Ley $\mathrm{N}^{\circ} 20.357$, de allí que nos referiremos a ella al tratar las agravantes ${ }^{22}$.

La desaparición forzada de personas está recogida en el artículo 6 de la ley chilena; se prevé con norma de concurso aparente con el secuestro.

\footnotetext{
bien históricamente se ha considerado al genocidio "the crime of crimes", no hay al día de hoy unanimidad al respecto. Tomando como indicador sólo la pena del homicidio -conducta punible según los casos como genocidio, crimen de guerra o crimen de lesa humanidad-para nuestra ley interna el delito más grave sería el genocidio (que contempla para esa conducta un rango de pena de presidio mayor en su grado máximo a perpetuo calificado), mientras los crímenes de guerra y de lesa humanidad entrañarían un disvalor inferior (con un marco de penas entre presidio mayor en su grado medio a perpetuo).

${ }^{20}$ Violación, esclavitud sexual, prostitución forzada, embarazo forzado, esterilización forzada o cualquier otra forma de violencia sexual de gravedad comparable.

${ }^{21}$ El Estatuto reseña, a título ejemplar, motivos políticos, raciales, nacionales, étnicos, culturales, religiosos, de género.

${ }^{22}$ Cfr. infra, II. 4. c).
} 
El crimen de apartheid ${ }^{23}$ no está contemplado en la ley chilena como tal, sino como circunstancia que prohíbe aplicar el mínimo de la pena, en el artículo 10 de la Ley $\mathrm{N}^{0} 20.357$.

En cuanto al hecho individual de "otros actos inhumanos de carácter similar que causen intencionalmente grandes sufrimientos o atenten gravemente contra la integridad física o la salud mental o física" (artículo 7 párrafo 1 letra k) del Estatuto de la Corte Penal Internacional), la ley chilena -como era esperable- no lo contempla, pues su amplitud resulta opinable desde el punto de vista del principio de legalidad tal como se lo entiende para el derecho penal interno en el sistema jurídico continental ${ }^{24}$. La ley tipifica sí atentados graves contra la salud física o mental, siguiendo la lógica de las lesiones en el Código Penal. Al respecto vale revisar el artículo $5 \mathrm{~N}^{\text {os }} 1$ y 2 , artículo $8 \mathrm{~N}^{\text {os }} 1$ y 2 de la Ley $\mathrm{N}^{\circ} 20.357$. El $\mathrm{N}^{\circ} 2$ se refiere específicamente a los experimentos biológicos.

\section{I.3. Genocidio ${ }^{25}$}

La Ley $\mathrm{N}^{\circ} 20.357$ dedica al genocidio sus artículos desde el 11 al 15.

La descripción del aspecto subjetivo que define al genocidio ${ }^{26}$ es equivalente en el Estatuto y en la ley, lo mismo que los grupos protegidos ${ }^{27}$, basándose ambos en el artículo 2 del Convenio para la Prevención y Sanción del Delito de Genocidio de 9 de diciembre de $1948^{28}$. En cuanto a los hechos individuales, las modificaciones que se

${ }^{23}$ Conforme al artículo 7 párrafo 2 letra h) del Estatuto de la Corte Penal Internacional, “[p]or "el crimen de apartheid' se entenderán los actos inhumanos de carácter similar a los mencionados en el párrafo 1 cometidos en el contexto de un régimen institucionalizado de opresión y dominación sistemáticas de un grupo racial sobre uno o más grupos raciales y con la intención de mantener ese régimen”.

${ }^{24}$ Cfr. al respecto, por todos, Mir Puig. S., Derecho Penal, Parte General, $7^{a}$ edición, B de F, Buenos Aires, 2007, p. 114 y ss., y entre los penalistas nacionales Cury Urzúa, E., Derecho Penal, Parte General, octava edición ampliada, 2005, Ediciones Universidad Católica de Chile, Santiago, 165 y ss.

${ }^{25}$ Cfr., por todos y con más antecedentes, Werle, G., Tratado de derecho penal internacional, Tirant Lo Blanch, Valencia, 2005, pp. 305 y ss. Vid. asimismo Fronza, E. "Genocide in the Rome Statute”, en Lattanzi, F./Schabas, W. (editores), Essays on the Rome Statute of the International Criminal Court, tomo 1 Il Sirente, Fagnano Alto, 1999, pp. 105 y ss.; Jørgensen, N. "The Definition of Genocide: Joining the Dots in the Light of Recent Practice”, en 1 International Criminal Law Review (2001), pp. 285 y ss.; Kittichaisaree, K., International Criminal Law, Oxford University Press, Oxford, 2001, pp. 67 y ss.; Lüders, B., Die Strafbarkeit von Völkermord nach dem Römischen Statut für den Internationalen Strafgerichtshof, Berliner Wissenschaftsverlag, Berlín, 2004; Schabas, W., Genocide in International Law, The Crime of Crimes, Cambridge University Press, Cambridge, 2000; Selbmann, F., Der Tatbestand des Genozids im Völkerstrafrecht, Leipziger Universitätsverlag, Leipzig, 2002; Zahar, A./Sluiter, G., International Criminal Law, Oxford University Press, Oxford (2008), pp. 155 y ss.

${ }^{26} \mathrm{La}$ intención de destruir, en todo o en parte, a un grupo nacional, étnico, racial o religioso, como tal.

${ }^{27}$ Nacional, étnico, racial o religioso.

${ }^{28}$ Está publicado como anexo de la Resolución 260 (III) de la Asamblea de Naciones Unidas (1948) y en 75 UNTS (1949), p. 277 y ss. Con todo, en la Historia de la Ley, op. cit., p. 92, en el informe de la Comisión de Derechos Humanos se deja constancia de una intervención de la señora Nelly Salvo, asesora del Ministerio de Justicia, que señala que la expresión "grupo nacional" comprende también a los grupos políticos. Lo mismo dijeron varios diputados. Si bien algunos derechos nacionales los incluyen -como el español por vía interpretativa o el francés de manera expresa-, su inclusión no constituye derecho penal internacional vigente. Habrá que esperar el criterio de los tribunales chilenos a este respecto. 
adoptan respecto del texto del Estatuto no restringen el ámbito de conductas punibles. Así, donde el Estatuto señala como conducta punible la "matanza de miembros del grupo", la ley chilena señala que lo es el "matar a uno o más miembros del grupo" (artículo 11 de la Ley $\mathrm{N}^{\circ}$ 20.357), quedando más allá de toda duda de que basta la muerte de una persona. Lo mismo sucede respecto de la lesión grave.

Por ello, en materia de genocidio serían punibles, conforme a la ley chilena, todas las conductas que caen bajo la competencia material de la Corte Penal Internacional, cumpliéndose así con el objetivo de declarado de la ley chilena.

Al igual que lo que ocurre en el Estatuto de la Corte Penal Internacional (artículo 25 párrafo 3 letra e), se castiga especialmente la instigación directa y pública al genocidio (artículo 15 de la Ley $\mathrm{N}^{\circ}$ 20.357).

\subsection{Crimenes de guerra ${ }^{29}$}

La ley chilena $\mathrm{N}^{\mathrm{0}} 20.357$ trata los crímenes de guerra en los artículos entre el 16 y el 34, dedicándoles un título especial. Fiel a la nomenclatura del Código Penal, la Ley No 20.357 se refiere a los “crímenes y delitos de guerra”. Primero se hará una referencia a los elementos comunes a los crímenes de guerra ${ }^{30}$ y luego a los hechos individuales.

\section{I.4.a) Elementos comunes}

El título dedicado a los crímenes de guerra se inicia con normas comunes a los delitos cometidos en conflictos armados internacionales y aquellos sin carácter internacional. La ley chilena se une así, al menos de manera nominal, a la tendencia internacional de castigar penalmente, dentro de lo posible, a las mismas conductas para los conflictos armados internacionales y aquellos sin ese carácter ${ }^{31}$. Con todo, avanzando en el articulado resulta que dicha distinción sí mantiene relevancia en el derecho interno, de allí que resulta interesante revisar la descripción legal de cada una de las dos clases de conflictos (artículo 17 letras a) y b) de la Ley $N^{\circ}$ 20.357). Entiende como conflicto

${ }^{29}$ Cfr., por todos y con más antecedentes, Werle, G., Tratado de derecho penal internacional, Tirant Lo Blanch, Valencia, 2005, pp. 419 y ss. Vid. asimismo Abi-Saab, G./Abi-Saab, R., "Les crimes de guerre", en Ascensio, H./Decaux, E./Pellet, A. (editores), Droit International Pénal, A, Pedone, París, 2000, pp. 265 y ss.; Arnold, R./Cottier, M., Dörmann, K./Viseur Sellers, P./Bennion, E./Zimmermann, A., “Article 8”, en Triffterer, O. (editor), Commentary on the Rome Statute of the International Criminal Court, Observers' Notes, Article by Article, $2^{a}$ edición, Beck, Munich, 2008, pp. 275 y ss.; Condorelli, L., "War Crimes and Internal Conflicts in the Statute of the International Criminal Court", en Politi, M./Nesi, G. (editores), The Rome Statute of the International Criminal Court, A Challenge to Impunity, Ashgate Publishing, Adlershot, 2001, pp. 107 y ss.; Venturini, G., "War Crimes in International Armed Conflicts", en Politi, M./Nesi, G. (editores), The Rome Statute of the International Criminal Court, A Challenge to Impunity, Ashgate Publishing, Adlershot, 2001, pp. 95 y ss.

${ }^{30}$ Son crímenes de guerra las violaciones graves del derecho internacional humanitario punibles conforme a él. Para que una conducta sea constitutiva de crimen de guerra, ésta debe tener una relación funcional con el conflicto armado de que se trate, cuya existencia debe ser conocida por el sujeto activo.

31 Entre las legislaciones que suelen tomarse como ejemplo en Chile, destaca esta tendencia en la alemana (Völkestrafgesetzbuch de 2002) y España (modificación al Código Penal de 2003). 
armado internacional el que surja entre dos Estados, o la ocupación de uno por otro sin que este último ofrezca resistencia. Llama la atención que, puestos a dar una definición, no se incluyan, para los efectos de la aplicación del derecho internacional humanitario, las luchas contra la opresión colonial o contra un régimen racista en el ejercicio de los pueblos a la libre determinación de conformidad con el artículo 1.4 del Primer Protocolo Adicional a los Convenios de Ginebra de 1949. Con ello, si se presentara este supuesto, los tribunales chilenos no podrían, en aplicación de esta ley, castigar como crímenes de guerra las conductas punibles sólo en conflictos armados internacionales.

La Ley $\mathrm{N}^{\circ} 20.357$ define, en cambio, al conflicto armado no internacional como “aquel que tiene lugar en el territorio de un Estado cuando existe un conflicto armado entre las autoridades gubernamentales y grupos armados organizados o entre tales grupos”. Excluye las situaciones de tensiones internas y disturbios interiores.

\section{I.4.b) Hechos individuales}

Por el gran número de hechos individuales que son constitutivos de crímenes de guerra y dados los limitados fines de este texto, se referirán solamente aspectos de especial interés, partiendo por los crímenes de guerra contra las personas.

El artículo 19 inciso 2 contiene una definición de actuar a traición que no se encuentra en el Estatuto, sin embargo está tomada de los Elementos de los Crímenes ${ }^{32}$ $\left(\mathrm{N}^{\circ} 1 \text { del 8.2.b) xi) y 8.2.e) ix) }\right)^{33}$.

Los artículos 20, 21 y 22 de la Ley $\mathrm{N}^{\circ} 20.357$ remiten a hechos individuales punibles como crímenes de lesa humanidad (ataques sexuales, tortura, exterminio, etc.). El artículo 20 inciso 2 agrega específicamente el secuestro extorsivo. Se homologan las conductas punibles en un conflicto armado internacional y en uno sin ese carácter.

El artículo 23 se refiere a los experimentos biológicos, que también integran el ámbito de competencia de la Corte Penal Internacional (artículo 8.2.b) x) de su Estatuto para conflictos armados internacionales, e) xi) para conflictos armados sin carácter internacional). Se tipifican también la declaración de que no se dará cuartel (artículo 24 de la Ley $N^{o}$ 20.357), el alistar y utilizar a niños soldados (artículo 26 inciso 1 de la Ley $\mathrm{N}^{\circ}$ 20.357), el desplazamiento de la población civil (artículo 26 inciso 2 de la Ley $\mathrm{N}^{\mathrm{o}} 20.357$ ) y las violaciones al debido proceso.

También entre las conductas punibles tanto en conflictos armados internacionales como en aquellos sin ese carácter, se encuentra el saquear (artículo 27 inciso 3 de la Ley $\mathrm{N}^{\circ} 20.357$ ) y, conforme al artículo 27 de la Ley $\mathrm{N}^{\circ} 20.357$, destruir o apropiarse "a

${ }^{32}$ Los denominados "Elementos de los Crímenes" son, lo mismo que las "Reglas de Procedimiento y Prueba”, textos cuya existencia y alcances están previstos en el Estatuto de la Corte Penal Internacional, en los artículos 9 y 51, respectivamente. Al respecto, cfr. por todos, Lee, R. (editor), The International Criminal Court, Elements of Crimes and Rules of Procedure, Transnational Publishers, Ardsley, 2001.

33 "Que el autor se haya ganado la confianza de una o más personas y les haya hecho creer que tenían derecho a protección o que él estaba obligado a protegerlas en virtud de las normas del derecho internacional aplicable a los conflictos armados". 
gran escala" de bienes de personas protegidas o del enemigo sin necesidades militares. Para estragos remite al Código Penal. El Estatuto de la Corte Penal Internacional, al describir estas conductas -artículo 8.2. a) iv) para conflictos armados internacionales, b) xiii), artículo 8.2 e) xii) para conflictos armados sin carácter internacional- no exige que la destrucción o apropiación deban ocurrir a gran escala, sin perjuicio de la referencia general de su artículo 8 párrafo $1^{34}$.

Se especifica luego una serie de conductas que la ley chilena castiga únicamente en caso de conflicto armado internacional. Entre ellas se incluye, a saber, el uso indebido de bandera blanca, insignia o uniforme del enemigo o de Naciones Unidas o Convenios de Ginebra (artículo 28) y una serie de conductas descritas en el artículo 29. Estas comprenden atacar poblados o edificios no defendidos que no son objetivos militares, atacar bienes civiles, atacar a una persona enemiga que se haya rendido, atacar monumentos históricos, obras de arte o lugares de culto. Incluyen, asimismo, atacar instalaciones que contengan "fuerzas peligrosas", a sabiendas de que se causaran ciertos efectos: daños extensos, duraderos y graves al medio ambiente, no proporcionales a la ventaja militar que se prevea; muertos o heridos civiles y daños a objetos civiles. La descripción de la conducta en el Estatuto (artículo 8.2 b) iv) para conflictos armados internacionales) no hace referencia a las fuerzas peligrosas. Si bien puede entenderse que si se actúa a sabiendas de que se producirán los efectos descritos se entiende que ha de tratarse de fuerzas peligrosas, no resulta claro por qué se introdujo esa especificación.

Entre las conductas del artículo 29 llama la atención que se incluyen algunas que conforme a la ley chilena son punibles sólo en conflictos armados con carácter internacional, en tanto que la Corte Penal Internacional puede conocerlas y eventualmente castigarlas tanto si tienen lugar en un conflicto armado internacional como en uno sin ese carácter. Se trata de las conductas de atacar a la población civil o personas civiles (artículo 8.2 b) i) del Estatuto de la Corte Penal Internacional para conflictos armados internacionales y artículo 8.2 e) i) para conflictos armados sin carácter internacional) y de atacar edificios dedicados a la religión, instrucción, las artes, las ciencias, beneficencia, hospitales y donde se agrupa a enfermos y heridos, siempre que no sean objetivos militares (artículo 8.2 b) ix) y xxiv) del Estatuto de la Corte Penal Internacional para conflictos armados internacionales y artículo 8.2 e) ii y iv) para conflictos armados sin carácter internacional).

Los artículos 30 al 34 de la Ley $\mathrm{N}^{\circ} 20.357$ se refieren a otros crímenes de guerra, sin presentar particularidades relevantes desde el punto de vista de las disposiciones del Estatuto de la Corte Penal Internacional.

En resumen, tratándose de conductas punibles como crímenes de guerra, si bien en general la ley chilena prevé castigo penal para las conductas que están bajo la competencia de la Corte, existen también algunas que la Corte puede castigar como crímenes de guerra en conflictos armados internos y que en el derecho penal interno de Chile no

34 "La Corte tendrá competencia respecto de los crímenes de guerra en particular cuando se cometan como parte de un plan o política o como parte de la comisión en gran escala de tales crímenes". 
tienen tal carácter. Si se cometieran y quedaran impunes, la Corte Penal Internacional podría, legítimamente, perseguirlas, haciendo uso de su jurisdicción complementaria. Para estos casos no se logra entonces la intención declarada al proponer la ley, sin que se haya siquiera discutido, en la historia de la ley, las razones para proceder de ese modo.

\section{DisPosiciones COMUNES Y COMPLEMENTARIAS}

La Ley $\mathrm{N}^{\circ} 20.357$ titula de este modo al contenido de sus artículos del 35 al 44.

\section{II.1. Generalidades}

En la Ley $\mathrm{N}^{\circ} 20.357$, las normas de parte general son escuetas, quedando atrás incluso frente al Estatuto de la Corte Penal Internacional. Se aplicará entonces, en gran medida, la parte general común del derecho penal interno. No se incluyen, a saber, normas para excluir la responsabilidad penal de menores de 18 años (artículo 26 del Estatuto de la Corte Penal Internacional), por lo que, respecto del Estatuto, se amplia el ámbito de los que pueden llegar a ser responsables por los crímenes tipificados en esta ley. Tampoco se regula la improcedencia de cargo oficial ${ }^{35}$ (artículo 27 del Estatuto de la Corte Penal Internacional). Si los tribunales chilenos constriñeran por este motivo el ámbito de los presuntamente responsables, la Corte Penal Internacional podría conocer del caso de que se trate.

Continuando con las omisiones, la Ley $\mathrm{N}^{\circ} 20.357$ no limita la procedencia de las eximentes de legítima defensa (artículo 31.1.c) del Estatuto de la Corte Penal Internacional) para defenderse sólo frente a ciertas agresiones o ataques ${ }^{36}$. Si bien la aplicación del estándar "racionalmente necesario" puede minimizar los efectos prácticos de la falta de

35 Este es un principio reconocido para crímenes contra el derecho internacional. Cfr., a saber, Damgaard, C., Individual Criminal Responsibility for Core International Crimes, Selected Pertinent Issues, Springer, Berlín, 2008, pp. 263 y ss.; Gaeta, P., "Official Capacity and Immunities”, en Cassese, A./Gaeta, P./Jones, J. (editores), The Rome Statute of the International Criminal Court: A Commentary, tomo 1, Oxford University Press, Oxford, 2002, pp. 975 y ss.; Hokema, G., Die Immunität von Staatsoberhäuptern, Lang, Frankfurt am Main, 2002; Oehler, D. Internationales Strafrecht, $2^{a}$ edición, Carl Heymann, Colonia, 1983, número marginal 521 y ss.; Saland, P., International Criminal Law Principles, en: Lee, R. (editor), The International Criminal Court, The Making of the Rome Statute, Kluwer Law International, La Haya, 1999, pp. 189, 202 y ss.; Schabas, W., An Introduction to the International Criminal Court, $2^{\text {a }}$ edición, Cambridge University Press, Cambridge, 2004, pp. 92 y ss..

${ }^{36}$ Cfr., al respecto, Ambos, K., La Parte General de un Derecho Penal Internacional, Fundación Konrad Adenauer-Temis-Duncker \& Humblot, Montevideo, 2005, pp. 457 y ss., 466 y ss.; Bantekas, I. "Defences in International Criminal Law”, en McGoldrick, D./Rowe, P./Donnelly, E. (editores), The Permanent International Criminal Court, Hart Publishing, Oxford, 2004, pp. 263 y 277 y ss.; Cassese, A., International Criminal Law, $2^{a}$ edición, Oxford University Press, Oxford, 2008, pág. 259 y ss., 280 y ss.; Cryer, R./Friman, H./Robinson, D./Wilmshurst, E., An Introduction to International Criminal Law and Procedure, Cambridge University Press, Cambridge, 2007, pág. 337 y ss.; Eser, A., “Article 31”, en Triffterer, O. (editor), Commentary on the Rome

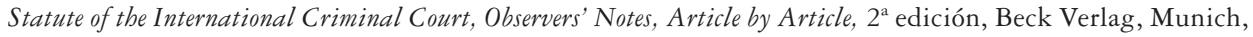
2008, pp. 863 y ss. 
regulación, en principio se podría llevar adelante una conducta tipificada como crimen de guerra, por ejemplo, para protegerse de cualquier clase de agresión ilegítima. La ley chilena tampoco regula particularmente supuestos de estado de necesidad ni de coacción (artículo 31.1.d) del Estatuto de la Corte Penal Internacional).

La Ley $N^{\circ} 20.357$ regula la responsabilidad por ordenar la comisión de crímenes contra el derecho internacional en el artículo $36^{37}$, en términos equivalentes a los del Estatuto de la Corte Penal Internacional, en el artículo 25.3.b). Lo mismo hace con la imprescriptibilidad de la acción penal y de la pena en su artículo $40^{38}$.

A continuación se comentan algunas disposiciones que requieren de un análisis más detenido.

\section{II.2. Responsabilidad del superior}

La ley chilena $\mathrm{N}^{\circ} 20.357$ dispone en su artículo 35 responsabilidad penal para el superior, civil o militar, distinguiendo dos supuestos: conforme al primero, se castiga como autor a quien, teniendo conocimiento de la comisión de un delito por otro no lo impidiera, pudiendo hacerlo. De acuerdo al segundo, se castiga al superior que, no pudiendo impedir el delito, no da aviso a la autoridad competente de que se ha cometido. En este último supuesto, la pena se rebajará en uno o dos grados.

Sin pretender agotar las críticas a esta disposición, sino que solamente comparándola con el artículo 28 del Estatuto de la Corte Penal Internacional ${ }^{39}$, que se ocupa de

${ }^{37}$ Cfr. el artículo 25.3.b) del Estatuto de la Corte Penal Internacional: "De conformidad con el presente Estatuto, será penalmente responsable y podrá ser penado por la comisión de un crimen de la competencia de la Corte quien: $[\ldots \ldots$ b) Ordene, proponga o induzca la comisión de ese crimen".

${ }^{38}$ Cfr. el artículo 29 del Estatuto de la Corte Penal Internacional: "Los crímenes de la competencia de la Corte no prescribirán". Este es un corolario del deber de castigar, también vastamente reconocido para crímenes contra el derecho internacional, Schabas, W., "Article 29", en Triffterer, O. (editor), Commentary on the Rome Statute of the International Criminal Court, Observers' Notes, Article by Article, $2^{\mathrm{a}}$ edición, Beck Verlag, Munich, 2008, pp. 845 y ss.; Van den Wyngaert, C./Dugard, J., "Non-Applicability of Statute of Limitations", en Cassese, A./Gaeta, P./Jones, J. (editores), The Rome Statute of the International Criminal Court: A Commentary, tomo 1, Oxford University Press, Oxford 2002, pp. 873 y ss.

39 Artículo 28 del Estatuto de la Corte Penal Internacional: “a) El jefe militar o el que actúe efectivamente como jefe militar será penalmente responsable por los crímenes de la competencia de la Corte que hubieren sido cometidos por fuerzas bajo su mando y control efectivo, o su autoridad y control efectivo, según sea el caso, en razón de no haber ejercido un control apropiado sobre esas fuerzas cuando: i) Hubiere sabido o, en razón de las circunstancias del momento, hubiere debido saber que las fuerzas estaban cometiendo esos crímenes o se proponían cometerlos; y ii) No hubiere adoptado todas las medidas necesarias y razonables a su alcance para prevenir o reprimir su comisión o para poner el asunto en conocimiento de las autoridades competentes a los efectos de su investigación y enjuiciamiento. b) En lo que respecta a las relaciones entre superior y subordinado distintas de las señaladas en el apartado a), el superior será penalmente responsable por los crímenes de la competencia de la Corte que hubieren sido cometidos por subordinados bajo su autoridad y control efectivo, en razón de no haber ejercido un control apropiado sobre esos subordinados, cuando: i) Hubiere tenido conocimiento o deliberadamente hubiere hecho caso omiso de información que indicase claramente que los subordinados estaban cometiendo esos crímenes o se proponían cometerlos; ii) Los crímenes guardaren relación con actividades bajo su responsabilidad y control efectivo; y iii) No hubiere adoptado todas las medidas necesarias y razonables a su alcance para prevenir o reprimir su comisión 
la misma materia, salta a la vista una serie de diferencias. La primera, y la más general, consiste en que la disposición chilena no se especifica que esta clase de responsabilidad se aplica para acciones de subalternos bajo el mando y control efectivos del superior de que se trate cuando éste no ha ejercido un control apropiado sobre ellos, sino que se expresa simplemente que las autoridades o jefes son responsables de la comisión "por otro" de crímenes contra el derecho internacional.

En segundo lugar, como se señalara, la ley chilena prevé sólo dos hipótesis, partiendo ambas de la base de que el superior sabe de la comisión del delito: en la primera dispone que es responsable el jefe o superior que sabe de la comisión de un delito si no lo impide, pudiendo hacerlo. Conforme al derecho penal internacional, en cambio, el superior es responsable, en esa constelación, si no ha adoptado todas las medidas necesarias y razonables para prevenir la comisión del delito. Se trata claramente de una forma de responsabilidad por una omisión contraria al deber ${ }^{40}$.

La segunda hipótesis que prevé la ley chilena es la del superior que sabe que se cometió un delito. Prevé su responsabilidad penal, con una pena disminuida, sólo si no pudo impedir el hecho y omitió dar aviso oportuno a la autoridad competente, en tanto que, conforme al derecho penal internacional, el superior es responsable en todos los casos en los que no haya adoptado todas las medidas necesarias y razonables a su alcance para reprimir su comisión o poner el asunto en conocimiento de las autoridades competentes para su investigación y su enjuiciamiento.

La ley chilena no distingue entre superiores civiles y jefes militares, pues no prevé las situaciones en las que para el derecho penal internacional es relevante esa distinción, que pretenden abarcar los casos de lo que en doctrina se llama "wilful blindness", en los que el superior se pone voluntariamente en una posición de no querer tomar conocimiento de los delitos, mismos que el jefe militar, si hubiera cumplido con sus deberes, hubiera debido conocer. Para los superiores civiles rige un estándar bastante menos exigente: Para ser responsables han de haber hecho, de manera deliberada, caso omiso de la información que indicase claramente la comisión del crimen. Los superiores, en estos casos de "wilful blindness", no tendrían responsabilidad penal conforme a la Ley $\mathrm{N}^{\circ} 20.357$, en tanto que la Corte Penal Internacional sí podría investigar, juzgar y eventualmente sancionar estos hechos.

\footnotetext{
o para poner el asunto en conocimiento de las autoridades competentes a los efectos de su investigación y enjuiciamiento".

40 Tratándose de una forma de responsabilidad propia del derecho penal internacional, la materia ha sido objeto de acabados estudios. Cfr., a saber, Ambos, K., La Parte General de un Derecho Penal Internacional, Fundación Konrad Adenauer-Temis-Duncker \& Humblot, Montevideo, 2005, pp. 295 y ss.; Cassese, A., International Criminal Law, $2^{\mathrm{a}}$ edición, Oxford University Press, Oxford, 2008, pp. 236 y ss.; Burghardt, B., Die Vorgesetztenverantwortlichkeit im völkerrechtlichen Straftatsystem-Eine Untersuchung zur Rechtsprechung der Internationalen Strafgerichtshöfe für das ehemalige Jugoslawien und für Ruanda, Berliner Wissenschaftsverlag, Berlín, 2008; Cryer, R./Friman, H./Robinson, D./Wilmshurst, E., An Introduction to International Criminal Law and Procedure, Cambridge University Press, Cambridge, 2007, pp. 320 y ss.; Zahar, A./Sluiter, G., International Criminal Law, Oxford University Press, Oxford, 2008, pp. 257 y ss.
} 
En suma, la disposición chilena, de aplicarse conforme a su temor literal, sin más, resultaría más amplia que la del Estatuto en cuanto a que la calidad de superior basta para que quien la detente adquiera responsabilidad penal por delitos cometidos por "otros"; en tanto que su ámbito de aplicación resulta más restringido si se tiene en cuenta que es necesario probar el conocimiento del delito, y en el caso de un delito ya consumado resulta necesario, además, que el superior no haya podido impedirlo. La regulación no abarca entonces a quien en cumplimiento de sus deberes de vigilancia y control debió haber sabido, y pudo impedir el hecho. Se abre así la puerta a casos de "wilful blindness" del superior.

\section{II.3. Actuar en cumplimiento de órdenes bajo coacción o error}

Nuestra ley nacional no contiene supuestos en los que la obediencia de una orden en cuanto a tal exima de responsabilidad criminal, sino que sólo se mencionan, en el artículo 38, los supuestos que se actúe cumpliendo una orden y además bajo coacción o error, vale decir, los eximentes parecen ser más bien estas circunstancias que el cumplimiento de la orden.

En el Estatuto de la Corte Penal Internacional se acepta la eximente de actuar bajo órdenes sólo para crímenes de guerra, y siempre que el subordinado haya estado legalmente a obedecer, no supiera que la orden es ilícita y tal ilicitud no fuera manifiesta ${ }^{41}$.

También la coacción (duress) está regulada en el Estatuto, pero por separado e independientemente del actuar bajo órdenes: exime de responsabilidad cuando es producto de una amenaza de muerte inminente o de lesiones corporales graves continuadas o inminentes para quien la recibe o para otra persona, por la que esta persona se vea compelida a actuar necesaria y razonablemente para evitar esa amenaza, siempre que no tuviera la intención de causar un daño mayor que el que se proponía evitar (artículo 31.1.d) del Estatuto de la Corte Penal Internacional) ${ }^{42}$.

${ }^{41}$ Sobre la eximente de actuar bajo órdenes en derecho penal internacional, cfr., a saber, Ambos, K., La Parte General de un Derecho Penal Internacional, Fundación Konrad Adenauer-Temis-Duncker \& Humblot, Montevideo, 2005, pp. 460 y ss.; Cryer, R., Prosecuting International Crimes, Selectivity and the International Criminal Law Regime, Cambridge University Press, Cambridge, 2005, pp. 292 y ss.; Dinstein, Y., "Defences", en McDonald, G./Swaak-Goldman, O. (editoras), Substantive and Procedural Aspects of International Criminal Law, The Experience of International and National Courts, tomo 1, Kluwer Law International, La Haya, 2000, pp. 369 y ss.; Triffterer, O., “Article 33”, en Triffterer, O (editor), Commentary on the Rome Statute of the International Criminal Court, Observers' Notes, Article by Article, $2^{\mathrm{a}}$ edición, Beck Verlag, Munich, 2008, pp. 915 y ss.; Zimmermann, A., "Superior Orders", en: Cassese, A./Gaeta, P./Jones, J. (editores), The Rome Statute of the International Criminal Court: A Commentary, tomo 1, Oxford University Press, Oxford, 2002, pp. 957 y ss.

${ }^{42} \mathrm{Al}$ respecto, cfr., a saber, Ambos, K., La Parte General de un Derecho Penal Internacional, Fundación Konrad Adenauer-Temis-Duncker \& Humblot, Montevideo, 2005, pp. 466 y ss.; Caccamo, V., "Lo stato di necesita”, en Enrico A. et al. (editores), Introduzione al Diritto Penale Internazionale, Giufffrè, Milán, 2006, pp. 247 y ss.; Cryer, R./Friman, H./Robinson, D./Wilmshurst, E., An Introduction to International Criminal Law and Procedure, Cambridge University Press, Cambridge, 2007, pp. 339 y ss.; Saland, P. "International Criminal Law Principles", en Lee, R.. (editor), The International Criminal Court, The Making of the Rome Statute, Kluwer Law International, La Haya, 1999, pp. 189 y ss.; Scaliotti, M., "Defences before the International 
Por último, el error, conforme a las disposiciones del Estatuto de la Corte Penal Internacional, exime de responsabilidad criminal siempre que como consecuencia de él no esté presente el elemento subjetivo del delito (artículo 32 del Estatuto de la Corte Penal Internacional), explicitándose eso sí la irrelevancia del error acerca de si la conducta de que se trata está bajo la competencia de la Corte Penal Internacional ${ }^{43}$.

La Ley $\mathrm{N}^{\circ} 20.357$ solamente regula de manera particular el error y la coacción en cuanto existe una orden, no al error y la coacción en general, explicitándose que es irrelevante el error en cuanto a la orden de cometer genocidio y crímenes de lesa humanidad (artículo 38 inciso 2). Ante la Corte Penal Internacional tampoco podría alegarse esta clase de error, pues se considera que estas órdenes son manifiestamente ilícitas (artículo 33.2 del Estatuto de la Corte Penal Internacional).

Las normas acerca del actuar bajo órdenes de la Ley $\mathrm{N}^{\circ} 20.357$ no obstan a la aplicación de los denominados "delitos de desobediencia", tipificados en el Código de Justicia Militar (artículos 287 y siguientes) ${ }^{44}$, pues la Ley N 20.357 se refiere sólo a las órdenes de cometer crímenes contra el derecho internacional, que no coinciden con los supuestos de punibilidad del Código de Justicia Militar. A saber, la comisión de crímenes contra el derecho internacional no puede considerarse como "servicios de guerra" por tratarse de conductas precisamente prohibidas en relación con un conflicto armado; de igual modo, las personas protegidas por el derecho internacional humanitario malamente podrían entenderse como comprendidas dentro del vocablo "enemigo" que emplea el Código de Justicia Militar chileno. De manera más general, la negativa de cometer crímenes contra el derecho internacional no atentaría contra los deberes y el honor militares, bienes protegidos en el Código de Justicia Militar, por lo que los ámbitos de protección de ambas disposiciones no llegan a colisionar.

Criminal Court: Substantive grounds for excluding criminal responsibility", primera parte: International Criminal Law Review 1 2001, pp. 111 y ss.; Venafro, E., "Lo stato di necessità", en Cassese, A./Chiavario M./ Giovannangelo De Francesco, G. (editores), Problemi Attuali della Giustizia Penale Internazionale, Giappichelli, Torino, 2005, pp. 103 y ss.

${ }^{43}$ Cfr. Ambos, K., La Parte General de un Derecho Penal Internacional, Fundación Konrad AdenauerTemis-Duncker \& Humblot, Montevideo, 2005, pp. 433 y ss.; Cassese, Antonio: International Criminal Law (2003), pág. 251 y ss.; Scaliotti, M., "Defences before the International Criminal Court: Substantive grounds for excluding criminal responsibility”, segunda parte, en International Criminal Law Review 2 (2002), pp. 1 y ss.; Stuckenberg, C., Vorstudien zu Vorsatz und Irrtum im Völkerstrafrecht, De Gruyter Recht, Berlín, 2007; Triffterer, O., "article 32", en Triffterer, O (editor), Commentary on the Rome Statute of the International Criminal Court, Observers' Notes, Article by Article, 2 ${ }^{\mathrm{a}}$ edición, Beck Verlag, Munich, 2008, pp. 895 y ss.

${ }^{44}$ El título VI del Código de Justicia Militar chileno, "Delitos contra los deberes y el honor militares", se refiere al castigo de algunos casos de desobediencia durante conflictos armados. Las conductas descritas en los artículos 287 y siguientes del Código de Justicia Militar no implican conductas constitutivas de crímenes contra el derecho internacional. Por lo demás, en el juicio que ha de preceder a la aplicación de las penas, mal podría aplicarse una pena a un militar por negarse a cometer un delito. 


\section{II.4. Agravantes y atenuantes}

Pasaremos revista a todas las previstas en el artículo 39 de la Ley $\mathrm{N}^{\circ} 20.357$.

II.4.a) Agravante de extensión considerable del número de personas ofendidas

Puede aplicarse para crímenes de lesa humanidad, de genocidio y crímenes y delitos de guerra. La formulación puede considerarse poco feliz, ya que estos crímenes, por su naturaleza, ofenden a la comunidad toda, y no sólo a la nacional (a saber, los crímenes de lesa humanidad se denominan también "crímenes contra la humanidad"). Con todo, buscando alguna interpretación que haga útil la norma, lo más seguro es que la expresión "personas ofendidas" vaya a interpretarse incluyendo solamente a aquellas más directamente afectadas con las conductas de que se trate.

\section{II.4.b) Atenuante de colaboración sustancial con el tribunal}

Conforme al texto de la ley, la colaboración sustancial con el tribunal que contribuya al esclarecimiento de los hechos, particularmente en lo que respecta al establecimiento de la responsabilidad de las demás personas que intervinieron en el acto punible, constituye una "atenuante calificada". Habrá que ver cómo se interpreta esta calificación. El Código Penal, en su artículo 68 bis, da cuenta del tratamiento penal que ha de darse cuando concurra una "atenuante muy calificada", pero no hay regulación respecto del tratamiento que ha de darse a una atenuante calificada sin más.

\section{II.4.c) Agravante de obrado por motivos de discriminación}

La ley dispone que la responsabilidad penal se agrave por haber obrado discriminatoriamente en razón de nacionalidad, raza, etnia, religión, género o consideraciones políticas o ideológicas. Si bien conforme al Estatuto de la Corte Penal Internacional la conducta de persecución ${ }^{45}$ sólo puede ser perseguida por ese tribunal "en conexión con otro crimen" de su competencia, por lo que no llama tanto la atención que la ley nacional la contemple como agravante y no como delito autónomo, sí resulta incomprensible que dicha agravante sólo rija para los crímenes de lesa humanidad, sin que en la Historia de la Ley se encuentre una explicación de por qué no se considera que existe también un disvalor adicional, de relevancia penal, si la discriminación por causas contrarias al derecho internacional acompaña a conductas constitutivas de genocidio o de crímenes de guerra.

${ }^{45}$ Artículo 7 letra h) del Estatuto de la Corte Penal Internacional "Persecución de un grupo o colectividad con identidad propia fundada en motivos políticos, raciales, nacionales, étnicos, culturales, religiosos, de género definido en el párrafo 3, u otros motivos universalmente reconocidos como inaceptables con arreglo al derecho internacional, en conexión con cualquier acto mencionado en el presente párrafo o con cualquier crimen de la competencia de la Corte". 


\section{II.5. Aplicación temporal de la ley}

Conforme a su artículo 44, Ley $\mathrm{N}^{\circ} 20.357$ sólo regirá para hechos cuyo principio de ejecución sea posterior a su entrada en vigencia (18 de julio de 2009) Para hechos anteriores regirá el derecho aplicable "a ese momento". Con esta fórmula, la ley no toma partido respecto a cuál sería este derecho aplicable.

\section{SobRE EL CUMPLIMIENTO DE LOS OBJETIVOS ANUNCIADOS AL LEGISLAR}

Existiendo -como ha quedado de manifiesto- más de algún supuesto en el que la punibilidad de conductas conforme a la ley chilena no abarca casos bajo la competencia de la Corte Penal Internacional, y extendiéndose ellos más allá de la necesaria precisión respecto de conductas punibles y penas que el respeto del principio de legalidad impone a la tipificación de conductas en nuestro derecho interno, resulta patente que no se ha cumplido cabalmente con el cometido político de la ley, cual fuera asegurar que el Estado de Chile pudiera ejercer jurisdicción castigando como crímenes de derecho internacional, conforme a su legislación interna, todas las conductas que conforme al Estatuto de Roma quedan bajo la competencia de la Corte Penal Internacional, a fin de asegurar que la Corte no llegue a estar jurídicamente facultada para ejercer su jurisdicción complementaria sobre hechos acaecidos en Chile.

Con todo, en los casos en los que las conductas que caen bajo la competencia de la Corte Penal Internacional no son punibles como crímenes de guerra, crímenes de lesa humanidad o genocidio en aplicación de la ley chilena pero sí lo son como delitos nacionales "ordinarios" -como ocurrirá frecuentemente- y son perseguidos conforme a los procedimientos establecidos en el derecho interno, la Corte no podrá ejercer su jurisdicción complementaria. Si en cambio hay impunidad, la Corte podría actuar si se cumple con los requisitos del examen de admisibilidad ${ }^{46}$.

\section{CONCLUSIONES}

No existiendo dudas respecto del ánimo que motivó a legislar en materia de crímenes de guerra, de lesa humanidad y de genocidio y habiéndose revisado comparado la legislación nacional con el Estatuto de la Corte Penal Internacional, cabe establecer, como conclusión general, que si bien la Ley $\mathrm{N}^{\circ} 20.357$ constituye un avance importante frente al vacío anterior a su dictación, el objetivo declarado por el legislador no se cumple a cabalidad.

46 Sobre el examen de admisibilidad, cfr. Cárdenas Aravena, C., Die Zulässigkeitsprïfung vor dem Internacionales Strafgerichtshof, Berliner Wissenschaftsverlag, Berlín, 2005. 
Así, en lo relativo a los crímenes de lesa humanidad, ya desde la descripción de ataque generalizado o sistemático contra una población civil, en el derecho nacional el ámbito de punibilidad queda constreñido si se lo compara con el derecho internacional $^{47}$. En lo que respecta a los hechos individuales, la punibilidad de la persecución como crimen de lesa humanidad está restringida en el derecho nacional respecto de los supuestos del Estatuto.

La tipificación del genocidio, en cambio, cumple con los fines de la legislación.

En cuanto a los crímenes de guerra, sin bien la mayoría de los supuestos de competencia material de la Corte Penal Internacional son punibles en la ley chilena, existen conductas que la Corte puede conocer tanto en cuanto a crímenes de guerra en conflictos armados internacionales como en cuanto a crímenes de guerra en conflictos sin ese carácter, en la ley chilena sólo pueden castigarse en relación con la primera hipótesis.

Respecto de la parte general, las pocas disposiciones que se incluyen en la ley dejan bastantes interrogantes abiertas. En el ámbito acotado del presente estudio, llama la atención que, existiendo un artículo referido a la responsabilidad del superior, no se abarquen todos los supuestos en las que ésta puede manifestarse. Así, en los casos en los que un superior militar, en cumplimiento de su deber de vigilancia y control debió saber que personas bajo su control estaban cometiendo crímenes contra el derecho internacional, y estaba en condiciones de evitarlo, la ley chilena no lo castiga como superior responsable. Si tal conducta queda impune, la Corte Penal Internacional sí podría juzgar al superior.

Parece pertinente examinar en lo sucesivo más acuciosamente los alcances de los proyectos de cuerpos legales, de modo de determinar si es efectivo que su texto sirve cabalmente a los fines específicos para los cuales se desea legislar.

\section{BIBLIOGRAFÍA}

Aмвоs, K., La Parte General de un Derecho Penal Internacional, Fundación Konrad Adenauer-Temis Duncker \& Humblot, Montevideo, 2005.

Ascensio, H./Decaux, E./Pellet, A. (editores), Droit International Pénal, A, Pedone, París, 2000.

Bassiouni, M., Crimes Against Humanity in International Criminal Law, $2^{a}$ edición, Kluwer Law International, La Haya, 1999.

BAntekas, I./NASH, S., Internacional Criminal Law, 3ra edición, Routledge-Cavendish, Londres, 2007.

BurghaRDT, B., Die Vorgesetztenverantwortlichkeit im völkerrechtlichen Straftatsystem-Eine Untersuchung zur Rechtsprechung der Internationalen Strafgerichtshöfe für das ehemalige Jugoslawien und für Ruanda, Berliner Wissenschaftsverlag, Berlín, 2008.

${ }^{47}$ Eventualmente en casos en los que la política a partir de la cual surge el ataque provenga de una organización sin las características que la ley chilena solicita, si las conductas de que se trate quedaren por ello sin persecución y eventual castigo, la Corte Penal Internacional podría legítimamente actuar ejerciendo su competencia sobre ellas. 
Cárdenas Aravena, C., "La Corte Penal Internacional y su relación con las jurisdicciones nacionales: El principio de complementariedad”, en Revista de Magíster y Doctorado en Derecho, Universidad de Chile. $N^{\circ} 1 / 2007$, pp. 123-138.

Cárdenas Aravena, C., "Los Crímenes del Estatuto de la Corte Penal Internacional en el derecho chileno, necesidad de una implementación”, en Política Criminal, Centro de Estudios de Derecho Penal de la Universidad de Talca, No 2/2006, pp. 1-17.

CÁrdenas Aravena, C., Die Zulässigkeitsprüfung vor dem Internationalen Strafgerichtshof, Berliner Wissenschaftsverlag, Berlín, 2005.

Cassese, A., International Criminal Law, $2^{a}$ edición, Oxford University Press, Oxford, 2008.

Cassese, A., "On Some Problematical Aspects of the Crime of Aggression", en Leiden Journal of International Law 20 (2007), pp. 841 y ss.

Cassese, A./Chiavario M./Giovannangelo De Francesco, G. (editores), Problemi Attuali della Giustizia Penale Internazionale, Giappichelli, Torino, 2005.

Cassese, A./Gaeta, P./Jones, J. (editores), The Rome Statute of the International Criminal Court: A Commentary, tomo 1, Oxford University Press, Oxford 2002.

Cazor Aliste, K. / Bordalí Salamanca, A., "La Corte Penal Internacional ante la Constitución de 1980 (comentarios al fallo del Tribunal Constitucional de fecha 8 de abril de 2002)", en Revista de Derecho, Universidad Austral de Chile, vol. XIII, diciembre 2002 , pp. 255-263.

Chile, Código de Justicia Militar. Sus distintas versiones se pueden consultar desde > http:// www.leychile.cl/Navegar?idNorma=18914< (visitado en febrero de 2010).

Cryer, R., Prosecuting International Crimes, Selectivity and the International Criminal Law Regime, Cambridge University Press, Cambridge, 2005.

Cryer, R./Friman, H./Robinson, D./Wilmshurst, E., An Introduction to International Criminal Law and Procedure, Cambridge University Press, Cambridge, 2007.

DamgandD, C., Individual Criminal Responsibility for Core International Crimes, Selected Pertinent Issues, Springer, Berlín, 2008.

Estatuto de Roma de la Corte Penal Internacional (en la versión corregida por los procesos verbales de 10 de noviembre de 1998, de 12 de julio de 1999, de 30 de noviembre de 1999 , de 8 de mayo de 2000, de 17 de enero de 2001 y de 16 de enero de 2002), A/ CONF.183/10, 17 de julio de 1998.

FronZa, E., "Genocide in the Rome Statute", en Lattanzi, F./Schabas, W. (editores), Essays on the Rome Statute of the International Criminal Court, tomo 1 Il Sirente, Fagnano Alto, 1999, pp. 105 y ss.

Hokema, G., Die Immunität von Staatsoberbäuptern, Lang, Frankfurt am Main, 2002.

Jørgensen, N., "The Definition of Genocide: Joining the Dots in the Light of Recent Practice", en 1 International Criminal Law Review (2001), pp. 285 y ss.

Kirk McDonald, G./Swaak-Goldman, O. (editoras), Substantive and Procedural Aspects of International Criminal Law, The Experience of International and National Courts, tomo 1, Kluwer Law International, La Haya, 2000.

Kittichaisaree, K., International Criminal Law, Oxford University Press, Oxford, 2001.

Lattanzi, G./Monetti, V. (editores), La Corte Penale Internazionale, Giuffrè, Milán, 2006.

LEE, R. (editor), The International Criminal Court, Elements of Crimes and Rules of Procedure, Transnational Publishers, Ardsley, 2001.

LEE, R. (editor), The International Criminal Court, The Making of the Rome Statute, Kluwer Law International, La Haya, 1999.

LüDERs, B., Die Strafbarkeit von Völkermord nach dem Römischen Statut für den Internationalen Strafgerichtshof, Berliner Wissenschaftsverlag, Berlín, 2004. 
McGoldrick, D./Rowe, P./Donnelly, E. (editores), The Permanent International Criminal Court, Hart Publishing, Oxford, 2004.

McDonald, G./SwaAK-Goldman, O. (editoras), Substantive and Procedural Aspects of International Criminal Law, The Experience of International and National Courts, tomo 1, Kluwer Law International, La Haya, 2000.

Meseke, S.: Der Tatbestand der Verbrechen gegen die Menschlichkeit nach dem Römischen Startus des Internationalen Strafgerichtshofs, Berliner Wissenschaftsverlag, Berlín 2004.

Nogueira Alcalá, H. "Consideraciones sobre el Fallo del Tribunal Constitucional Respecto del Tratado de Roma que Establece la Corte Penal Internacional” en Ius et Praxis, Universidad de Talca, 8(1): 2002, pp. 563-581.

OeHLer, D. Internationales Strafrecht, 2a edición, Carl Heymann, Colonia, 1983.

Politi, M./Nesi, G. (editores), The International Criminal Court and the Crime of Aggression, Ashgate Publishing, Adlershot, 2004, pp. 97 y ss.

Politi, M./Nesi, G. (editores), The Rome Statute of the International Criminal Court, A Challenge to Impunity, Ashgate Publishing, Adlershot, 2001, pp. 107 y ss.

Presidencia de la República, Mensaje de S. E. el Presidente de la República con el que se inicia un proyecto de acuerdo que aprueba el Estatuto de Roma de la Corte Penal Internacional, adoptado dicha ciudad el 17 de julio de 1998, contenido en el acta final de la Conferencia Diplomática de Plenipotenciarios de las Naciones Unidas sobre el Establecimiento de la Corte Penal Internacional, de fecha 10 de noviembre de 1998, consultado en >http://sil. congreso.cl/pags/index.html< (visitado en febrero de 2010).

Protocolo Adicional a los Convenios de Ginebra del 12 de agosto de 1949 relativo a la protección de las víctimas de los conflictos armados sin carácter internacional (Protocolo II, de 1977). Consultado en $>$ http://www.cicr.org/web/spa/sitespa0.nsf/html/protocolo-II $<$ (visitado en febrero de 2010).

Scaliotti, M., "Defences before the International Criminal Court: Substantive grounds for excluding criminal responsibility", primera parte: International Criminal Law Review 1 2001, pp. 111 y ss.

Scaliotti, M., "Defences before the International Criminal Court: Substantive grounds for excluding criminal responsibility", segunda parte, en International Criminal Law Review 2 (2002), pp. 1 y ss.

SCHABAs, W., An Introduction to the International Criminal Court, $2^{\mathrm{a}}$ edición, Cambridge University Press, Cambridge, 2004.

Schabas, W., Genocide in International Law, The Crime of Crimes, Cambridge University Press, Cambridge, 2000.

Selbmann, F., Der Tatbestand des Genozids im Völkerstrafrecht, Leipziger Universitätsverlag, Leipzig, 2002.

Senado, Moción de los senadores Alberto Espina, José Antonio Gómez, Hernán Larraín, Pedro Muñoz, Mariano Ruiz-Esquide, de 11 de marzo de 2009. Puede ser consultada en >http:// recursoslegales.bcn.cl/jspui-rl/bitstream/10221.3/3840/2/HL20357.pdf < (visitado en febrero de 2010).

SENADO, Oficio del Senado No 558/SEC/09, de 25 de junio de 2009. consultado en $>$ http://sil. congreso.cl/pags/index.html< (visitado en febrero de 2010).

Stuckenberg, C., Vorstudien zu Vorsatz und Irrtum im Völkerstrafrecht, De Gruyter Recht, Berlín, 2007.

Tribunal Constitucional, sentencia de 8 de abril de 2002, puede ser consultada en $>$ http:// www.tribunalconstitucional.cl/index.php/sentencias/download/pdf/274< (visitado en febrero de 2010). 
TriffTerer, O. (editor), Commentary on the Rome Statute of the International Criminal Court, Observers' Notes, Article by Article, 2a edición, Beck Verlag, Munich, 2008.

Varios Estados, legislaciones nacionales de implementación pueden ser revisadas en $>$ http:// www.legal-tools.org/en/access-to-the-tools/national-implementing-legislation-database $/<$ (visitado en febrero de 2010).

Werle, G., Tratado de derecho penal internacional, Tirant Lo Blanch, Valencia, 2005.

Zahar, A./Sluiter, G., International Criminal Law, Oxford University Press, Oxford, 2008. 